\title{
Development of Urinary Concentrating Capacity in Weaning Rats
}

\author{
SVEN RANE, ANITA APERIA, PETER ENEROTH, AND STEFAN LUNDIN \\ Department of Developmental Physiology, St. Göran's Children's Hospital and Huddinge Hospital, the \\ Department of Endocrinology, Karolinska Hospital, Karolinska Institute, Stockholm, and the Ferring Research
} Laboratories, Malmö, Sweden

\begin{abstract}
This study describes the development of the capacity to concentrate urine in 10- to 40-day-old rats that were normally weaned between 16 and 18 days, breast-fed until day 20 , or abruptly weaned on day 16. Urine osmolarity after $24 \mathrm{~h}$ dehydration was significantly lower in 10 than in 20- and in 20- than in 40-day-old rats. The most pronounced increase occurred between 16 and 20 days in the three groups. The increase in urine osmolality was paralleled by an increase of papillary $\mathrm{Na}$ and urea concentrations. The length of the papilla increased linearly from day 10 to 40 . Serum arginine vasopressin levels were not significantly different in dehydrated 10- and 20-day-old rats. Serum corticosterone increased significantly between 10 and 20 days of age in both normally weaned and breastfed rats. The rise was accelerated between days 16 and 18 and paralleled the rise in urinary concentrating capacity. Adrenalectomy on day $\mathbf{1 6}$ abolished the increases in urine osmolality and papillary $\mathrm{Na}$ and urea concentrations, but not the growth of the papilla between days 16 and 20 . The urinary concentrating capacity could be precociously induced by treatment with betamethasone from day 10 to 17 but not from day 17 to 20 . Our results indicate that the accelerated development of urine concentrating capacity at the time of weaning is independent of dietary composition and most likely modulated by glucocorticoid hormones. (Pediatr Res 19: 472-475, 1985)
\end{abstract}

\section{Abbreviations}

NW, normally weaned PS, prolonged suckling AW, abruptly weaned

The development of the capacity to concentrate urine mainly occurs postnatally. In newborn infants (1-3), rats (4), and dogs (5) dehydration and the administration of $\mathrm{ADH}$ generally result in a urine osmolarity that is or only slightly hypertonic to plasma osmolality.

In the rat, the greatest change in urinary concentrating capacity $(4,6)$ is observed during the first $3 \frac{1 / 2}{2}$ wk of life. Weaning occurs during the $3 \mathrm{rd}$ wk of life in rats. It is well established that the development of the gastrointestinal tract is accelerated at the

Received August 27, 1984; accepted January 16, 1985.

Reprint address Anita Aperia, Department of Developmental Physiology, St. Göran's Children's Hospital, Box 12500, S-112 50 Stockholm, Sweden.

Supported by Grants B84-19X-03644-13A and B84-19X-02049-16A from the Swedish Medical Research Council and grants from the Swedish Baby Food Industry. time of weaning (7). These developmental changes are of importance for the dietary transition from milk to solid food. Since this transition also entails a decrease in the water turnover, one may expect developmental changes in the control of water metabolism during weaning.

It is the purpose of our study to describe the development of the urinary concentrating capacity in rats during the weaning period. In the small intestine the maturation of a series of enzymes and transport systems is accelerated at the time of weaning $(7,8)$. There is considerable evidence that the acceleration of maturation is induced not by the change in food composition but by the rapid increase in corticosterone production that occurs in weaning rats (8). In order to differentiate between the effect of a change in the food composition and the effect of intrinsic endocrine changes at the time of weaning we studied three groups of animals: rats that were NW, rats AW on day 16 , and rats fed only breast-milk (PS) up to the age of 20 days. Serum corticosterone was determined in all groups of rats. Since we observed that the capacity to concentrate urine developed in parallel to a rise in serum corticosterone levels, we further investigated the role of glucocorticoid hormones for the development of the concentrating capacity by studying adrenalectomized and betamethasone-treated animals.

\section{METHODS}

The studies were performed on male Sprague-Dawley rats whose ages ranged from $10-20$ and from $40-42$ days. The younger rats were subdivided into three groups with regard to the weaning pattern.

$N W$ rats. The pups were kept with their dam until day 19 , but they also had free access to food, Anticimex R-3 rat food. The protein content of this food corresponds to $21 \%$ of the calories.

$P S$ rats. The pups were kept with their dam until the day of the study. They did not have access to rat food. The dam was removed from the cage for $1 \mathrm{~h}$ twice daily for feeding. The weight gain in this group was significantly less than in group 1 .

$A W$ rats. The pups were separated from their dam on day 16 and were fed only Anticimex R-3 rat food.

One group of rats was adrenalectomized at the age of 16 days and studied at 20 days. Adrenalectomies were performed under light ether anaesthesia. Following a midline incision the adrenals were gently dissected free from the perirenal fat and the vascular pedicle was clamped. After adrenalectomy the rats were given normal saline to drink.

Three groups of rats were treated with betamethasone (Glaxo) $60 \mu \mathrm{g} \cdot 100 \mathrm{~g}^{-1}$ intramuscularly. This dose has been shown to have a maximal inductive effect on renal cortical enzymes taken from infant rats (9). The rats in the three groups were treated from day $10-13$, day $14-17$, and day $17-20$, respectively. 
Separate control groups were used for the adrenalectomized and betamethasone-treated rats. The size of the litters was reduced to four to six pups. The NW rats weighed $23 \pm 0.5 \mathrm{~g}$ at 10 days, $42 \pm 1 \mathrm{~g}(\mathrm{NW}), 28 \pm 0.3 \mathrm{~g}(\mathrm{PS})$, and $42.5 \pm 2.1 \mathrm{~g}(\mathrm{AW})$ at 20 days and $172 \pm 2 \mathrm{~g}$ at 40 days. An attempt was made to use as few litters as possible for each protocol.

To assess maximal urine concentrating capacity, the rats were deprived of food and fluid for $24 \mathrm{~h}$. The suckling rats were removed from their dams. At the time of the study the animals were anaesthetized by an intraperitoneal injection of Inactin, (Byk-Gulden), $80 \mathrm{mg} \cdot 100 \mathrm{~g}^{-1}$. Following a midline abdominal incision, the urinary tract was visualized, the bladder punctured, and urine samples were aspirated immediately from the bladder. The kidneys were then removed and a median slice, including the intact papilla, was excised from each kidney. Before removal of the papilla, its length was measured under a microscope. The measurements had an accuracy of $\pm 0.10 \mathrm{~mm}$. The papilla was then removed from the rest of the medulla and rapidly frozen on dry ice. The entire procedure from opening the abdomen until freezing the tissue took approximately $1 \mathrm{~min}$. All the animals survived the $24 \mathrm{~h}$ of dehydration and the brief anaesthesia afterward.

A cardiac puncture was performed to obtain blood samples in unanaesthetized dehydrated rats for arginine vasopressin determinations and in unanaesthetized normally hydrated rats for corticosterone determinations.

Analytical procedures. Urine and homogenized papillary tissue were analyzed for sodium, urea, and osmolarity. Material from three to five rats was used for each determination. In a few rats in each age group the water content of the papilla was determined as the difference between the wet weight and the dry weight. The dry weight was obtained by drying the tissue at $100^{\circ} \mathrm{C}$ until a constant weight was achieved. The water content decreased from $93 \%$ at 10 days of age to $87 \%$ at 40 days of age. Sodium concentrations were determined using a flamphotometer. Urea was determined using an enzymatic colorimetric method (Boehringer-Mannheim). Osmolality was determined with a freezepoint osmometer.

Corticosterone in $50-\mu \mathrm{l}$ aliquots of serum was determined by radioimmunoassay, as described in detail previously (10). The lowest level of corticosterone that could be distinguished from zero concentration was $10 \mathrm{nmol} /$ liter. The intra- and interassay coefficients of variation were 7 and $16 \%$, respectively.

Arginine vasopressin concentration in serum was determined by means of radioimmunoassay, as described in detail previously (11). The serum was first extracted by the acetone-petroleum method (12).

Calculations. Values are given as the mean $\pm \mathrm{SE}, p$ values $<$ 0.05 were considered significant. Analysis of variance was used to compare the results obtained from different age groups.

\section{RESULTS}

Development of concentrating capacity in NW rats. The developmental changes in urine osmolarity and papillary tissue concentration of urea and sodium from day 10 to 20 are shown in Figure 1. Urine osmolarity was significantly lower in 10 - to 12 day-old rats than in 18- to 20-day-old rats $(p<0.01)$ and significantly lower in 18- to 20-day-old rats than in 40 - to $42-$ day-old rats $(p<0.05)$. Tissue urea and sodium concentrations were significantly lower in 10- to 12-day-old rats than in the older rats. The greatest increase occurs from day 16 to 18 .

The relationship between urine osmolarity and age seems to fit a monoexponential expression $(r=0.93)$ better than a linear expression $(r=0.81)$.

The length of the papilla increased significantly from $10-12$ days of age $(1.4 \pm 0.1 \mathrm{~mm})$ to 40 days of age $(3.5 \pm 0.1 \mathrm{~mm})$. The relationship between age and papillary length fitted an exponential expression with the same probability as a linear expression $(r=0.94)$.
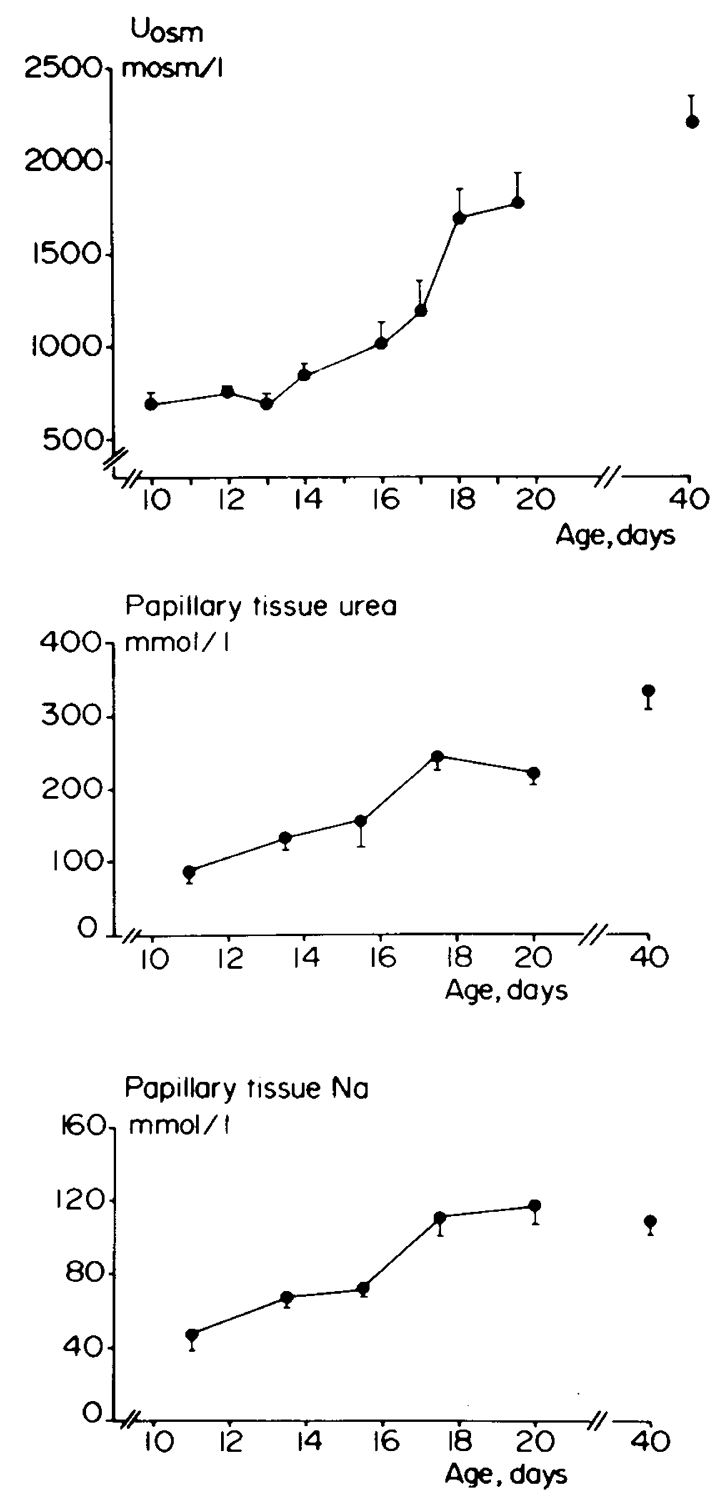

Fig. 1. Urine osmolarity, papillary urea concentration, and papillary $\mathrm{Na}$ concentration following $24 \mathrm{~h}$ of food and fluid deprivation in NW 10- to 40-day-old rats. Values are the means of 3-11 determinations. The bars represent $\mathrm{SE}$.

Development of urinary concentrating capacity during abnormal weaning patterns. Figure 2 illustrates the development of the urinary concentrating capacity in the PS group. An exponential increase in urine osmolality $(r=0.90)$ was found from 10 to 20 days of age. From 14-16 to 18-20 days there was a significant increase in the papillary tissue concentrations ( $\mathrm{mmol} / \mathrm{liter}$ ) of both urea $(131 \pm 17 \rightarrow 196 \pm 20)$ and sodium $(60 \pm 4 \rightarrow 93 \pm$ 8 ) in the PS rats ( $n=$ four to five in each group). A rapid increase in urine osmolarity from day 16 to 20 also was observed in the rats that were AW at the age of 16 days (data not shown). Urine osmolarity was not significantly different in 18- to 20-day-old NW, PS, and AW rats.

Hormone levels. Serum corticosterone increased significantly from 10 to 20 days of age in both the NW rats and the PS rats (Fig. 3, upper panel). The increase was steepest between 16 and 18 days of age. Serum arginine vasopressin was determined after $24 \mathrm{~h}$ of dehydration (Fig. 3, lower panel). Serum arginine vasopressin was not significantly different in 10- and 20-day-old rats and in 20 - and 40-day-old rats. It was significantly higher in 40than in 10-day-old rats.

Development of urinary concentrating capacity in betametha- 


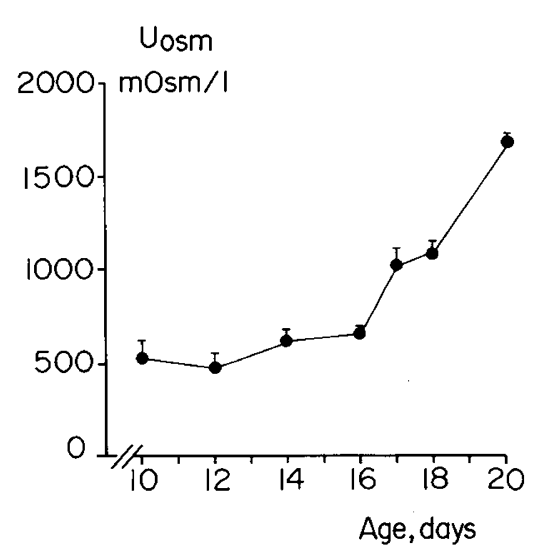

Fig. 2. Urinary osmolarity following $24 \mathrm{~h}$ of food and fluid deprivation in PS rats. Values are the means of four to six determinations. The bars represent SE.
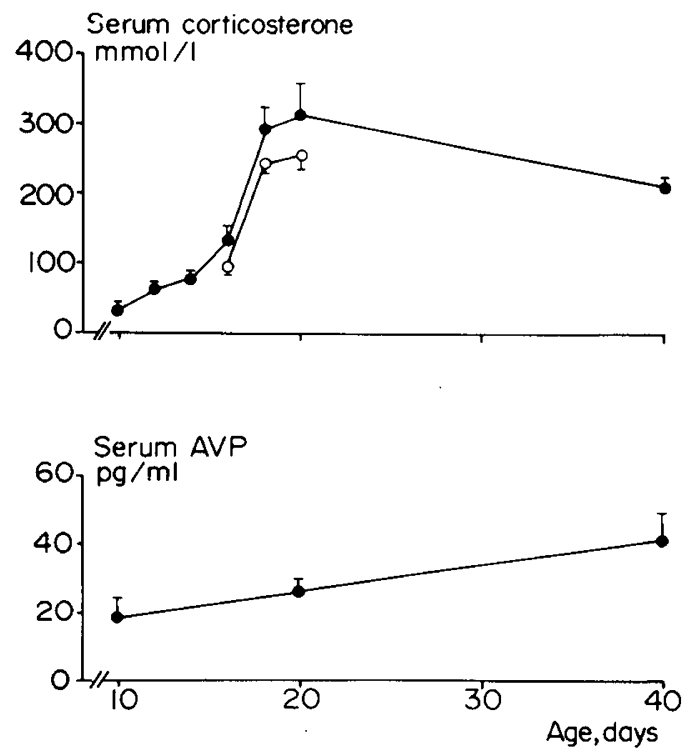

Fig. 3. Serum corticosterone was determined in normally hydrated rats that were NW $(\Theta)$ or PS $(O)$. Values are the means of five determinations. The bars represent SE. Serunı arginne vasopressin was determined in dehydrated NW rats. Serum from two to three rats was pooled. Values are the means of five determinations. The bars represent the SE.

sone-treated and adrenalectomized rats. Betamethasone significantly increased urinary concentrating capacity in rats aged 1017 days, i.e. just before or during the period when there is a rapid increase in urinary concentrating capacity and serum corticosterone (Fig. 4). However, betamethasone did not further increase the urinary concentrating capacity when it had almost reached its maximum, i.e. in 17 - to 20 -day-old rats.

In the adrenalectomized 20-day-old rats urinary concentrating capacity and papillary tissue concentration of sodium and urea were the same as in 16-day-old control rats but significantly lower than in 20-day-old control rats (Table 1). The growth of the papilla was not inhibited by adrenalectomy. The length of the papilla was $3.1 \pm 0.1 \mathrm{~mm}$ in the adrenalectomized 20-dayold rats and $1.93 \pm 0.1 \mathrm{~mm}$ in the 16-day-old control rats.

\section{DISCUSSION}

This study shows that the development of urinary concentrating capacity in rats is accelerated at the time of weaning. The accelerated development of the concentrating mechanisms probably is due to accelerated renal maturation since the serum levels of antidiuretic hormone were not significantly different in dehydrated 10 - and 20 -day-old rats.

It has been reported previously that the production of corticosterone increases at the time of weaning (8). The results of our study suggest that this is a biological event caused by intrinsic factors since it occurs in both the NW rats and rats that continue to be fed only breast-milk. Several observations in this study imply that maturation of the concentrating capacity at the time of weaning is modulated by glucocorticoid hormones. The increase in corticosterone production paralleled the development of the urinary concentrating capacity in both groups of rats; adrenalectomy at 16 days of age abolished the development of the concentrating capacity; and the capacity to concentrate urine was significantly increased by treatment with a synthetic glucocorticoid hormone from day 10 to 17 but not from day 17 to 20 .

In accordance with previous reports (13) we found that the development of the capacity to concentrate urine at 10 to 20 days of age is accompanied by an increase in papillary sodium and urea concentrations. Adrenalectomy at day 16 not only prevented the increase in urine concentrating capacity but also the increase in papillary sodium and urea concentrations. High papillary sodium and urea concentrations depend on several factors, including active $\mathrm{Na}$ transport in the thick ascending limb of Henle and the action of ADH on the collecting ducts. Both Na-K-ATPase activity (5) and ADH-dependent cAMP production $(14,15)$ in the collecting duct cells could be targets for

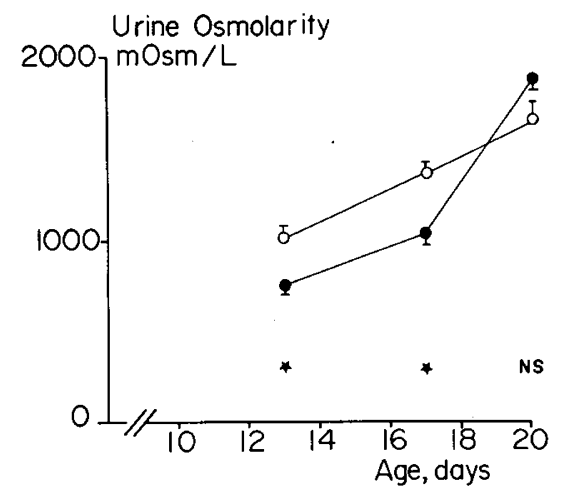

Fig. 4. Urine osmolarity following $24 \mathrm{~h}$ food and fluid deprivation in control rats $(\Theta)$ and rats treated with betamethasone $60 \mu \mathrm{g} \cdot 100 \mathrm{~g}^{-1}$ for 3 days $(O)$. There are four to six rats in each group. The bars represent $\mathrm{SE}$. The asterisk denotes a significant difference between control rats and betamethasone-treated rats.

Table 1. Effect of adrenalectomy on the development of urinary concentrating development of urinary concentrating capacity during the weaning period (mean $\pm S E)^{*}$

\begin{tabular}{lccc}
\hline \multicolumn{1}{c}{$\begin{array}{c}\text { Age } \\
\text { (days) }\end{array}$} & $\begin{array}{c}\text { Urine osmolarity } \\
\text { (mosmol/liter) }\end{array}$ & $\begin{array}{c}\text { Papillary tissue } \\
\mathrm{Na} \\
\left(\mathrm{mmol} / \mathrm{kg} \mathrm{H}_{2} \mathrm{O}\right)\end{array}$ & $\begin{array}{c}\text { Pary tisue urea } \\
(\mathrm{mmol} / \mathrm{kg} \\
\left.\mathrm{H}_{2} \mathrm{O}\right)\end{array}$ \\
\hline 20 & $804 \pm 36 \dagger$ & $153 \pm 17 \dagger$ & $61 \pm 4 \dagger$ \\
adx at 16 days & $n=8$ & $n=6$ & $n=6$ \\
20 & $1926 \pm 94$ & $235 \pm 27$ & $109 \pm 18$ \\
control & $n=8$ & $n=7$ & $n=7$ \\
& & & \\
16 & $987 \pm 64$ & $139 \pm 28$ & $64 \pm 4$ \\
control & $n=8$ & $n=5$ & $n=5$ \\
\hline
\end{tabular}

* Urine osmolarity and papillary tissue concentrations of sodium and urea were recorded after $24 \mathrm{~h}$ of food and fluid deprivation.

$\uparrow$ Significantly different from 20 -day-old control rats. There was no significant difference between 20-day-old adx rats and 16-day-old control rats with regard to any of the parameters studied. 
glucocorticoid. The activity of Na-K-ATPase, the enzyme mainly responsible for active sodium transport, has been shown to increase in the thick ascending limb of Henle from infancy to adulthood in rabbits (16). It is well established that Na-K-ATPase activity depends on the action of glucocorticoids (17). In preparations using proximal tubular cells it has been shown that $\mathrm{Na}-$ $\mathrm{K}$-ATPase in immature cells can be prematurely induced by exogenous glucocorticoid administration (9). Immature collecting ducts $(18,19)$ have a lower sensitivity to $\mathrm{ADH}$ than mature collecting ducts. There is evidence that ADH-dependent cAMP can be induced by glucocorticoid hormones $(14,15)$. These data suggest that glucocorticoids induce one or more of the transport systems necessary for the creation of a hypertonic medullary interstitium.

It is generally agreed that increased protein intake and increased urea availability induced by urea infusion can enhance the capacity to concentrate urine. An increased protein intake has been shown to enhance the renal concentrating capacity in human infants aged 2-4 months (20). On the other hand, it has been shown that 10-day-old rats cannot utilize urea as well as 20-day-old rats to create a hypertonic papillary interstitium (21). Since the accelerated development of the urinary concentrating capacity was found in both the NW and the PS group, an alteration in protein intake is not a likely explanation of the accelerated development of the urinary concentrating capacity at the time of weaning.

It is well established from comparative species studies that the length of the loop of Henle is correlated to the capacity to develop a papillary osmotic gradient (22). We observed that the growth of the papilla, which may be taken as an index of the growth of the long loops of Henle, increased from 10-40 days of age. Edwards et al. (4) found that the most dramatic growth of the superficial loops of Henle in infant rats occurred between the ages of 10 and 16 days. In the present study adrenalectomy at day 16 inhibited the development of urinary concentrating capacity and the increase in papillary sodium concentration, but not the growth of the papillar. Thus it seems unlikely that growth of the loops is responsible for development of the concentrating capacity at the time of weaning.

\section{REFERENCES}

1. Polacek E, Vocel J, Neugebauerova L, Sebkova M, Vechetova E 1965 The osmotic concentrating ability in healthy infants and children. Arch Dis Child 40:291-295
2. Svenningsen NW, Aronson AS 1974 Postnatal development of renal concentration capacity, as estimated by DDAVP-test, in normal and asphyxiated neonates. Biol Neonate 25:230-241

3. Winberg $J 1959$ Determination of renal concentration capacity in infants and children without renal disease. Acta Paediatr Scand 48:318-328

4. Edwards BR, Mendel DB, LaRochelle Jr FT, Stern P, Valtin H 1981 Postnatal development of urinary concentrating ability in rats: changes in renal anatomy and neurohypophysial hormones. In: Spitzer A (ed) The Kidney during Development. Masson Publishing, New York, pp 233-240

5. Horster M, Valtin H 1971 Postnatal development of renal function: micropuncture and clearance studies in the dog. J Clin Invest 50:779-795

6. Falk G 1955 Maturation of renal function in infant rats. Am J Physiol 181:157170

7. Henning SJ 1981 Postnatal development: coordination of feeding, digestion and metabolism. Am J Physiol 241:G199-G214

8. Henning SJ, Sims JM 1979 Delineation of the glucocorticoid-sensitive period of intestinal development in the rat. Endocrinology 104:1158-1163

9. Igarashi Y, Aperia A, Larsson L, Zetterström R 1983 Effect of betamethasone on Na-KATPase activity and basal and lateral cell membranes in proximal tubular cells during early development. Am J Physiol 245:F232-F237

10. Nielsen OG, Toftegård R, Eneroth $P 1980$ Effects of acrylo nitrile on rat liver cytochrome P-450, denzo(A)pyrene metabolism and serum hormone levels. Toxicol Lett 6:399-404

11. Aperia A, Herin P, Lundin S, Melin P, Zetterström R 1984 Regulation of renal water excretion in newborn full-term infants. Acta Pediatr Scand 73:717 721

12. Robertson GL, Mahr EA, Athar S, Sinka T 1973 Development and clinical application of a new method for the radioimmunoassay of arginine vasopressin. J Clin Invest 52:2340-2352

13. Yunibhand von $P$, Held $U 1965$ Nierenmark und Urinosmolalität nach der Geburt bei der Ratte unter Flüssigkeitsentzug. Helv Physiol Acta 23:91-96

14. Jackson BA, Braun-Werness JL, Kusano E, Dousa TP 1983 Concentrating defect in the adrenalectomized rat. J Clin Invest 72:997-1004

15. Schwartz MJ, Kokko JP 1980 Urinary concentrating defect of adrenal insufficiency. J Clin Invest 66:234-242

16. Schmidt U, Horster M 1977 Na-K-activated NaKATPase: activity maturation in rabbit nephron segments dissected in vitro. Am J Physiol 233:F55-F60

17. Chignell DF, Titus $\mathrm{E} 1966 \mathrm{Effect}$ of adrenal steroids on $\mathrm{Na}^{+}$- and $\mathrm{K}^{+}$-requiring adenocine triphosphatase from rat kidney. J Biol Chem 241:5083-5089

18. Rajerison RB, Butlen D, Jard S 1976 Ontogenic development of antidiuretic hormone receptors in rat kidney: comparison of hormonal binding and adenylate cyclase activation. Mol Cell Endocrinol 4:271-285

19. Schlondorff D, Weber H, Trizna W, Fine LG 1978 Vasopressin responsiveness of renal adenylate cyclase in newborn rats and rabbits. Am J Physiol 234:F16-F21

20. Edelmann Jr CM, Barnett HL, Troupkou V 1960 Renal concentrating mechanisms in newborn infants. Effect of dietary protein and water content, role of urea and responsiveness to antidiuretic hormone. J Clin Invest 39:10621068

21. Trimble ME 1970 Renal response to solute loading in infant rats: relation to anatomical development. Am J Physiol 219:1089-1097

22. Burg MB, Stephenson JL 1978 Transport characteristics of the loop of Henle. In: Andreoli T, Hoffman J, Fanestil D (eds) Physiology of Membrane Disorders, Plenum, New York, pp 661-679 